\title{
КОМПЛЕКСНЫЙ ПОДХОД К ЛЕЧЕНИЮ ШИЗОТИПИЧЕСКОГО РАССТРОЙСТВА В УСЛОВИЯХ СТАЦИОНАРА
}

\section{AN INTEGRATED APPROACH TO THE TREATMENT OF SCHIZOTYPAL DISORDER IN A HOSPITAL SETTING}

\section{A. Igovskaya A. Berezkin \\ V. Akhmetova T. Tarasova}

Summary. This article provides an overview of the psychotherapeutic management of patients with schizotypal disorder using various approaches to psychotherapy in a hospital setting. The main method of treating patients is psychopharmacological, which includes a wide range of traditional drugs - neuroleptics, tranquilizers, antidepressants, normotimics. At the heart of psychotherapeutic work with a patient is a psychotherapeutic contract, which includes a clear division and acceptance of responsibility by the psychologist / psychotherapist and the patient, about the agreed distribution of rights and responsibilities between the participants in the psychotherapeutic process. Social conditions are noted as one of the factors that improve the treatment and rehabilitation process of patients. The dynamics of the state before and after treatment is shown. The effectiveness of complex (medication and psychotherapeutic) treatment of the considered category of patients was also analyzed. A course of treatment with the use of neuroleptics, tranquilizers, antidepressants, vascular drugs and a course of psychotherapy is described. The psychotherapeutic effect is shown in patients with schizotypal disorder through polymodal psychotherapy, where transactional analysis was used as a basic, integrating approach with the inclusion in the process of individual techniques from clientcentered, symbolic and cognitive-behavioral psychotherapy. The author concludes that the effective optimal treatment of patients with schizotypal disorder in a hospital setting is a combination of the use of drug and psychotherapeutic methods.

Keywords: schizotypal disorder, social adaptation, psychotherapy, therapeutic cooperation (compliance), psychopathic symptomatology.
Иговская Анна Станиславовна

К.м.н., дочент, Российский университет дружбы народов (РУДН)

igovskaya@gmail.com

Березкин Александр Сергеевич

К.м.н., Российский университет дружбы народов

(РУДН)

asberezkin@yandex.ru

Ахметова Валерия Валерьевна

К.м.н., дочент, Российский университет дружбы народов (РУДН)

lera-axmetova@yandex.ru

тарасова Татьяна Павловна

К.м.н., дочент, Российский университет дружбы народов (РУДН)

zlova-tp@rudn.ru

Аннотация. В настоящей статье на основе литературных данных приводится обзор психотерапевтического ведения пациентов с шизотипическим расстройством с применением различных подходов психотерапии в условиях стационара. Основной метод лечения пациентов - психофармакологический, который включает в себя широкий спектр традиционных препаратов - нейролептики, транквилизаторы, антидепрессанты, нормотимики. В основе психотерапевтической работы с пациентом лежит психотерапевтический контракт, который включает четкое разделение и принятие ответственности психологом/психотерапевтом и пациентом, о согласованном распределении прав и обязанностей между участниками психотерапевтического процесса. Отмечаются социальные условия как один из факторов, улучшающих лечебно-реабилитационный процесс пациентов. Показана динамика состояния до и после лечения. Также проанализирована эффективность комплексного (медикаментозного и психотерапевтического) лечения рассматриваемой категории больных. Описывается курс лечения с применением нейролептиков, транквилизаторов, антидепрессантов, сосудистых препаратов и курса психотерапии. Показано психотерапевтическое воздействие у больных с шизотипическим расстройством посредством полимодальной психотерапии, где в качестве базового, интегрирующего подхода использовался транзактный анализ с включением в процесс отдельных приемов из клиент-центрированной, символообразной и когнитивно-поведенческой психотерапии. Авторы приходят к выводу, что эффективным оптимальным лечением пациентов с шизотипическим расстройством в условиях стационара является сочетание применения медикаментозных и психотерапевтических методов.

Ключевые слова: шизотипическое расстройство, социальная адаптация, психотерапия, терапевтическое сотрудничество (комплаенс), психопатоподобная симптоматика. 
Психотерапевтическое ведение пациентов с расстройством шизотипического спектра с применением различных по $\triangle$ хо ов психотерапии

U изотипическое расстройство - обширный паттерн социальной и межличностной недостаточности, выражающийся в остром дискомфорте и уменьшении способности к интреперсональным взаимоотношениям, сочетающийся с когнитивно-перцептивными нарушениями и эксцентричным поведением. Склонность к декомпенсациям у таких больных сопоставима с описанной отечественными авторами вялотекущей (малопрогредиентой, латентной) формой шизофрении [13]. В зарубежной психиатрической литературе шизотипическое расстройство характеризуется как «пограничный синдром» (borderline syndrome) и входит в круг расстройств между неврозом и психозом [19].

Диагностика и лечение шизотипического расстройства представляет собой одну из важнейших задач клинической психиатрии, которая направлена на улучшение качества жизни пациентов и повышение их социальной адаптации [5].

Нами проведен анализ состояния научных исследований в рассматриваемой области. Исследование публикаций по вопросам качества психиатрической помощи населению, в том числе пациентам с шизотипическим расстройством $[5,11,14,16]$, свидетельствует о том, что этой важной проблеме не уделяется должного внимания.

Имеющиеся разработки по рассматриваемой проблеме не могут быть полностью внедрены, поскольку они, в основном, не в полной мере адаптированы к местным структурам психиатрической помощи, не учитывают эпидемиологические и социодемографические особенности конкретного региона, его материальные и кадровые возможности [7].

Имеющиеся исследования направлены на изучение разных аспектов проблемы психотерапевтического ведения пациентов с шизотипическим расстройством в условиях стационара $[5,9,11,13,17,20]$. Рассмотрим некоторые из них, представляющие наибольшую актуальность.

В литературе отмечены разработки индивидуальных программ лечения, реабилитации и адаптации пациентов с шизотипическим расстройством в стационаре [13]. По мнению авторов, они позволили минимизировать или компенсировать негативное влияние различных факторов, обновить способность пациентов исполнять социальные роли в обществе и повысить их уровень жизни. Так, например, в ходе стационарного лечения в научно-практическом психоневрологическом центре имени 3.П.Соловьева Департамента здравоохранения города Москвы [13] вместе с фармакологическим лечением основных и сопутствующих заболеваний лечебный процесс включает комплекс проверенных, показавших свою эффективность нелекарственных методик: психотерапевтические (используются разнообразные техники в аспекте когнитивно-поведенческой, психоаналитической и гуманистической моделей психотерапии), аутогенная тренировка, БОС-тренинг, музыкотерапия, релаксационная и дыхательная гимнастика, танцедвигательная терапия, гипербарическая оксигенация, разнообразные физиопроцедуры и иные методики [3]. Условия клиники оказывают важное опосредованное оздоравливающее воздействие, что, в свою очередь, обуславливает благоприятные условия для осуществления психотерапевтических вмешательств [12].

В большинстве исследований $[7,13]$ описывается в качестве основного метода лечения пациентов с рассматриваемым заболеванием психофармакологический, включающий в себя следующие виды традиционных препаратов: нейролептики, транквилизаторы, антидепрессанты, нормотимики. Анализ клинической картины не показывает нехватку симптоматики ни в структуре эмоционально-волевой сферы, ни в мышлении. Между тем, в специально проведенных экспериментальных пробах были обнаружены ошибки суждений в виде опоры на слабые признаки, присутствие своеобразно отдаленных ассоциаций. Больным были присущи: тестирование реальности, осознанность, критичность по отношению к болезненным переживаниям и мотивация к выздоровлению, что доказывает необходимость оказания им психотерапевтической помощи [13].

В литературе принцип выстраивания психотерапевтической работы с больными базируется на многофакторности влияния в зависимости от преобладания в структуре психических нарушений ведущих синдромов и личностных проявлений. Главная цель терапии развитие конструктивных проблемно-разрешающих копинг-стратегий, управление эмоциональным дистрессом, повышение в целом успешности адаптации в тех социальных условиях, в которых находится пациент. Коррекция базируется на принципах гуманистической модели: конгруэнтность, принятие, поддержка, эмпатия [10]. Ее целью является поддержание навыков восприятия социальной поддержки, аффилиации. На первоначальном этапе работы устанавливается эмоциональный контакт, формируются доброжелательная 
и непринужденная атмосфера, доверительные отношения.

Психотерапевтическая работа базируется на установлении психотерапевтического контракта (ПК), включающего четкое разделение и принятие ответственности психологом/психотерапевтом и пациентом, а также взаимное распределение прав и обязанностей между участниками психотерапевтического процесса. В течении всего психотерапевтического процесса ПК постоянно проверяется и корректируется психотерапевтом/психологом и пациентом. Кроме того, процедура заключения ПК иногда представляет собой психотерапевтическую методику первоначального этапа взаимодействия психолога/психотерапевта и пациента и имеет лечебное значение [8].

На основе терапевтического взаимодействия и крепкого доверительного контакта больным в процессе рациональной психотерапии на базе применения рационального мышления осуществляется корректировка внутренней картины заболевания, в первую очередь когнитивного элемента. Осуществляется увеличение критического отношения к болезни, разъясняется природа диагноза, сокращается ощущение фатальности и неизбежности, объясняются особенности действия назначенного психотропного лечения, образуется привязанность к осуществляемой психофармакотерапии. Также на данном этапе больной в процессе психотерапии учится понимать себя, ценить сильные черты своего характера, а также сглаживать недостатки [13].

Второй блок работы состоит из проработки психопатологических феноменов. На данном этапе используется когнитивно-поведенческая модель психотерапии, которая представляет собой краткосрочный подход, часто используемый в большинстве клинических реабилитационных программ [5]. В комплексе с назначенной психофармакотерапией она эффективна в лечении шизотипического расстройства [1, 4]. Обучая определению и исправлению собственных неадекватных когниций, психотерапевт формирует условия для того, чтобы больной со временем стал сам для себя психотерапевтом [7, 15, 16, 17, 18, 20, 21].

В литературе подробно описывается применение разнообразных когнитивных техник (в частности, декатастрофизация и расширение набора навыков преодоления трудностей), с помощью которых изменяется отношение больного к заболеванию, что способствует ему лучше понять происходящее, восстанавливает ощущение контроля над собственной жизнью и усиливает ответственность за свое поведение. В процессе терапии разные сложные мысли поэтапно прорабатываются с применением разнообразных техник данного направления психотерапии (декатастрофизиция, рефрейминг, реатрибуция и др.). Также немаловажное значение уделяется работе по созданию модели здорового поведения. Она осуществляется в виде разыгрывания субъективно трудных для больного ситуаций и обучения более адаптивным реакциям [11].

В некоторых исследованиях в психотерапевтической работе внимание уделяется и родственникам больных с рассматриваемым заболеванием, которые, иногда, понимают или ввиду срабатывания механизма психологической защиты вытесняют или отрицают болезнь пациента, что отрицательно сказывается на его психоэмоциональной сфере. В процессе комплексной семейной психотерапии осуществляется корректировка дисфункциональной семейной системы, что способствует изменению межличностных отношений, ликвидации эмоциональных нарушений, сформировавшихся ввиду заболевания пациента, угнетающих одного или нескольких членов семьи.

По результатам проведенного исследования [13] по шкале Бека у 51,1\% первоначально поступивших в стационар пациентов выявляются признаки высокой выраженности депрессии, 48,9\% - умеренно выраженной. По итогам прохождения вышеописанного курса лечения у $40 \%$ пациентов отмечается умеренно выраженная депрессия, у $60 \%$ - незначительная степень тяжести данных проявлений.

Результаты исследования [13] по данным опросника по измерению личностной и ситуационной тревоги Спилберга демонстрируют, что выраженность данных показателей после комплексного вышеописанного лечения в стационаре снижается, что также свидетельствует об эффективности проводимого лечения: 55,5\% и 44,5\% выраженная и умеренно выраженная личностная тревожность до лечения; 11,1\%, 57,8\% и 31,1\% выраженная, умеренно выраженная и низкая степень тревожности после лечения соответственно; 57,8\% выраженная степень тяжести показателя ситуационной тревожности и 42,2\% умеренная степень выраженности до лечения и 3\%, 40\%, 57\% выраженная, умеренная и низко выраженная степень ситуационной тревожности после лечения.

\section{Терапевтические особенности шизотипического расстройства в периол стационарного лечения}

В своем исследовании И.Н. Винникова, Н.В. Лазько и др. [2] подробно описывают анамнез, особенности протекания рассматриваемого заболевания и его лечение. Так, лечение в стационаре проводится на основании принципа этапности [6]. После начальной 
общей седации (клозапин - 25 мг на ночь) на адаптационно-диагностическом этапе в период активной терапии назначался нейролептик широкого спектра действия - зуклопентиксол (10 мг/сут) в сочетании с трифлуоперазином (15 мг/сут) под «прикрытием» корректоров (тригексифенидил - 6 мг/сут) для влияния на процессуальные нарушения мышления. Для коррекции аффективных расстройств в схему лечения включался карбамазепин (600 мг/сут).

В последующем, при стабилизации состояния пациента в качестве базового препарата использовался зуклопентиксол, но уже в виде депо (200 мг- 1 мл внутримышечно 1 раз в 3 недели). Доза трифлуоперазина снижается до 7,5-10 мг/сут. [2].

К периоду подготовки к выписке (после вышеуказанного лечения) у пациентов с рассматриваемым заболеванием истероформные проявления во многом редуцировались, сгладились нарушения мышления, настроение было ровным, без суточных колебаний. При экспериментально-психологическом исследовании на заключительном этапе нарушений мышления у пациентов практически не выявлялось, они были настроены на конструктивное взаимодействие с окружающими, планы на будущее носили конкретный, реальный характер. Для возобновления трудовой деятельности пациентов корректируется терапия следующим образом: в качестве базового препарата назначается кветиапин (100 мг на ночь) в сочетании с нормотимиком ламотриджином (50 мг/сут). К концу 4-го этапа лечения в психическом состоянии пациента констатировалась терапевтическая ремиссия. [2].

Итак, вышеописанные лечебно-реабилитационные мероприятия в условиях стационара были направлены, прежде всего, на сглаживание истероформных психопатоподобных проявлений, стабилизацию аффективной сферы, коррекцию идеаторных нарушений, что помогло восстановить когнитивные функции и определить возможности межличностной и социальной адаптации.

\section{Эффективность комп^ексного лечения больных с шизотипическим расстройством}

Интерес представляют некоторые исследования, изучавшие результаты лечения больных с шизотипическим расстройством на основании проведения обследования у 40 пациентов с рассматриваемым заболеванием [9]. Проводился комплексный курс лечения с применением нейролептиков, транквилизаторов, антидепрессантов, сосудистых препаратов и курс психотерапии. Психотерапевтическое воздействие у больных с шизотипическим расстройством проводилось посред- ством полимодальной психотерапии, где в качестве основного, интегрирующего подхода использовался транзактный анализ с включением в процесс отдельных приемов из клиент-центрированной, символообразной и когнитивно-поведенческой психотерапии [14].

После проведенного лечения у больных шизотипическим расстройством динамика нейропсихологических показателей продемонстрировала увеличение общей активности, темпа при выполнении проб, что свидетельствует об улучшении функционирования глубоких подкорковых структур. Снизились модально-неспецифические нарушения памяти. Существенно уменьшилась тормозимость следов памяти в условиях гетерогенной интерференции, что обусловлено улучшением функционирования медиальных отделов коры. Об этом свидетельствует также значительное уменьшение утраченных элементов при воспроизведении фигуры Рей-Тейлор. Произошло достоверное улучшение функционирования премоторных отделов. Увеличилась эффективность в интеллектуальной деятельности при решении арифметических задач, выполнении вербально-логических операций. Указанное свидетельствует об улучшении функционирования префронтальных зон [9].

Таким образом, при изначально большей сохранности правого полушария имело место улучшение работы и левого полушария в процессе терапии. В сфере оптико-пространственных представлений значительно повысилась продуктивность при воспроизведении фигуры Рей-Тейлор. Отмечалась положительная динамика в сфере зрительного гнозиса и, следовательно, затылочных отделов коры. Уменьшилась степень выраженности симптомов аритмии. Увеличилась продукция существительных при проведении свободного ассоциативного эксперимента, что говорит об уменьшении дисфункций со стороны височной области левого полушария. Также отмечалось улучшение функционирования нижнетеменных и верхнетеменных отделов коры левого полушария [9].

В литературе отмечается, что после проведенного лечения существенно улучшилось функционирование со стороны глубоких подкорковых структур, которые при первичном исследовании были наиболее нарушены. Значительное улучшение со стороны префронтальных отделов, теменно-затылочных и в меньшей степени левой височной области носит, вероятно, вторичный характер [9].

Анализ показателей самооценки по методике Дембо-Рубинштейн показал более или менее выраженные изменения по всем шкалам: «счастье - горе»; «оптимист - пессимист»; «надежда — отчаяние»; «волевой безвольный»; «сильный — слабый характер»; «умный - 
глупый»; «уверенный - робкий», «здоровье-болезнь», «общительный - замкнутый» [9].

\section{ВывО $\triangle \mathrm{b}$}

Вышеприведенное подтверждает, что описанные в настоящем обзоре модели психотерапии в сочетании с фармакологическим лечением в условиях открытого психиатрического стационара являются достаточно эффективными. В качестве преимущества можно отметить вовлечение пациентов во внутрибольничную среду, которая помогает использовать динамику взаимоотношений, формирует возможность расширить социальную сферу контактов, улучшить навык общения, находить в лице других пациентов поддержку и понимание, перенимать конструктивные паттерны поведения. В результате чего облегчается включение пациента в микросоциальное окружение, что значительно способствует стабилизации психического состояния.
По результатам проведенного обзора можно прийти к выводу, что предложенные комплексы методик являются достаточно информативными для объективной диагностики нарушений высших психических функций и эмоциональных нарушений у больных шизотипическим расстройством и могут применяться для исследования динамики состояния данной категории пациентов в ходе их лечения. Нами было обращено внимание на тот факт, что у изучаемой категории пациентов, по результатам нейропсихологического исследования, на первый план выходят нарушения со стороны глубоких подкорковых структур и медиальных отделов коры, вызванные, скорее всего, изменением эмоционального состояния пациентов. Поэтому редукция аффективных нарушений способствует улучшению общемозгового функционирования. В связи с чем, по нашему мнению, оптимальным путем совершения такой коррекции может служить комплексное применение медикаментозных и психотерапевтических методов.

\section{ЛИТЕРАТУРА}

1. Бабин С. М., Шлафер А.М. Комплаенс-терапия больных шизофренией. Практическое руководство. — М.: ИД Городец, 2020. - 160 с.

2. Винникова И.Н., Лазько Н.В., Дмитриев А.С. и др. Клинические и терапевтические особенности шизотипического расстройства в период стационарного принудительного лечения // Практика судебно-психиатрической экспертизы.—- М.: Нац. мед. исследовательский центр психиатрии и наркологии им. В.П. Сербского. 2018. № 56. С. 182-190.

3. Гехт А.Б., Дачевская И.И., Акжигитов Р.Г. Навстречу 100-летию ГБУЗ НПц Психоневрологии ДЗМ // Сб. статей «Пограничные психические расстройства: фундаментальные, клинические и социальные аспекты».—- М.: Федеральный центр общественного здоровья, 2014.- С. 9-20.

4. Еричев А.Н., Моргунова А.М., Коцюбинский А.П. Когнитивно-поведенческая психотерапия больных с параноидным бредом // Российский психиатрический журнал. 2011. № 4. С. 45-50.

5. Иванец Н.Н., Ефремова Е.Н. Клиническая характеристика начальных этапов шизотипического расстройства // Медицинские технологии. Оценка и вы6ор. 2012. № 112 (4). С. 23-26.

6. Котов В.П. Принудительное лечение в психиатрическом стационаре.- М.: ИОИ, 2009. - 308 c.

7. Можны П., Шлепецки М. Когнитивно-бихевиоральная терапия психических расстройств. — М.: Институт гуманитарных исследований, 2015. - 1072 c.

8. Назыров Р.К., Ташлыков В.А., Ремесло М.Б., Сазонов В.Я., Федоряка Д.А., Холявко В.В., Ляшковская С.В., Чернов П.Д. Формирование «психотерапевтического контакта» в диаде «врач — пациент» В системе психотерапевтической помощи: методические рекомендации. - СПб.: СПб НИПнИ им. В.М. Бехтерева, 2014. - 24 с.

9. Потапова Т.Ф., Чупрова В.А. Изучение эффективности комплексного (медикаментозного и психотерапевтического) лечения больных с посттравматическим стрессовым расстройством, неврозами и шизотипическим расстройством // Сб. трудов Всероссийской науч.-практ. конф. «Психологическое здоровье человека: жизненный ресурс и жизненный потенциал» (23-24 ноября 2012 года, Красноярск). — Красноярск: Верс0, 2012. - С. 222-229

10. Роджерс К. Консультирование и психотерапия. Новейшие подходы в психологической практике.— М.: ИОИ, 2015. — 200 с.

11. Тетерина М.Н., Мешандин И.А. К вопросу о возможностях когнитивно-поведенческого направления психотерапии // Психическое здоровье. 2017. T. 15. № 5 (132). C. 76-81.

12. Тетерина М.Н., Мешандин И.А. Клиент-центрированный подход к психотерапии в психоневрологической практике // Психическое здоровье. 2018. Т. 16. № 10. С. 19-23.

13. Тетерина М.Н., Мешандин И.А. Психотерапевтическое сопровождение в лечении пациентов с расстройством шизотипического спектра в условиях открытого психиатрического стационара // Психиатрия, психотерапия и клиническая психология. 2019. Т. 10. № 3. С. 502-509.

14. Тукаев Р.Д. Российская мультимодальная психотерапия. Часть 2: Теоретические перспективы // Психотерапия. 2004. № 1. С. 18-23.

15. Харитонов С.В., Семке В.Я. Оценка когнитивно-поведенческой и рациональной терапии врачами и пациентами с личностными расстройствами // Сибирский Вестник психиатрии и наркологии. 2010. № 6 (63). С. 70-73.

16. Цыганков Б.Д., Джангильдин Ю.Т., Добровольская Ю.В. Основные направления и модальности в современной психотерапии: учебное пособие.- М.: МГМСУ, 2004.- 60 c.

17. Ellis A. Humanistic psychotherapy: The rational-emotive approach. New York: McGraw-Hill. 1973.— 272 p. 
18. Hofmann S. The Efficacy of Cognitive Behavioral Therapy: A Review of Meta-analyses // Cognitive Therapy and Research. 2012. № . 36 (5). pp. $427-440$.

19. Keefe R.S., Goldberg T.E., Harvey P.D. et al. The Brief Assessment of Cognition in Schizophrenia: reliability, sensitivity, and comparison with a standard neurocognitive battery // Schizophrenia Research. 2004. № 68. pp. 283-297

20. National Collaborating Centre for Mental Health (UK). Depression: The Treatment and Management of Depression in Adults (Updated Edition). Leicester (UK): British Psychological Society, 2010. - 707 p.

21. Wenzel A., Brown G.K., Beck A.T. Cognitive therapy for suicidal patients: Scientifi c and clinical applications. Washington: American Psychological Association. 2009. $-377 p$.

() Иговская Анна Станиславовна ( igovskaya@gmail.com ), Березкин Александр Сергеевич ( asberezkin@yandex.ru ), Ахметова Валерия Валерьевна ( lera-axmetova@yandex.ru ), Тарасова Татьяна Павловна ( zlova-tp@rudn.ru ).

Журнал «Современная наука: актуальные проблемы теории и практики»

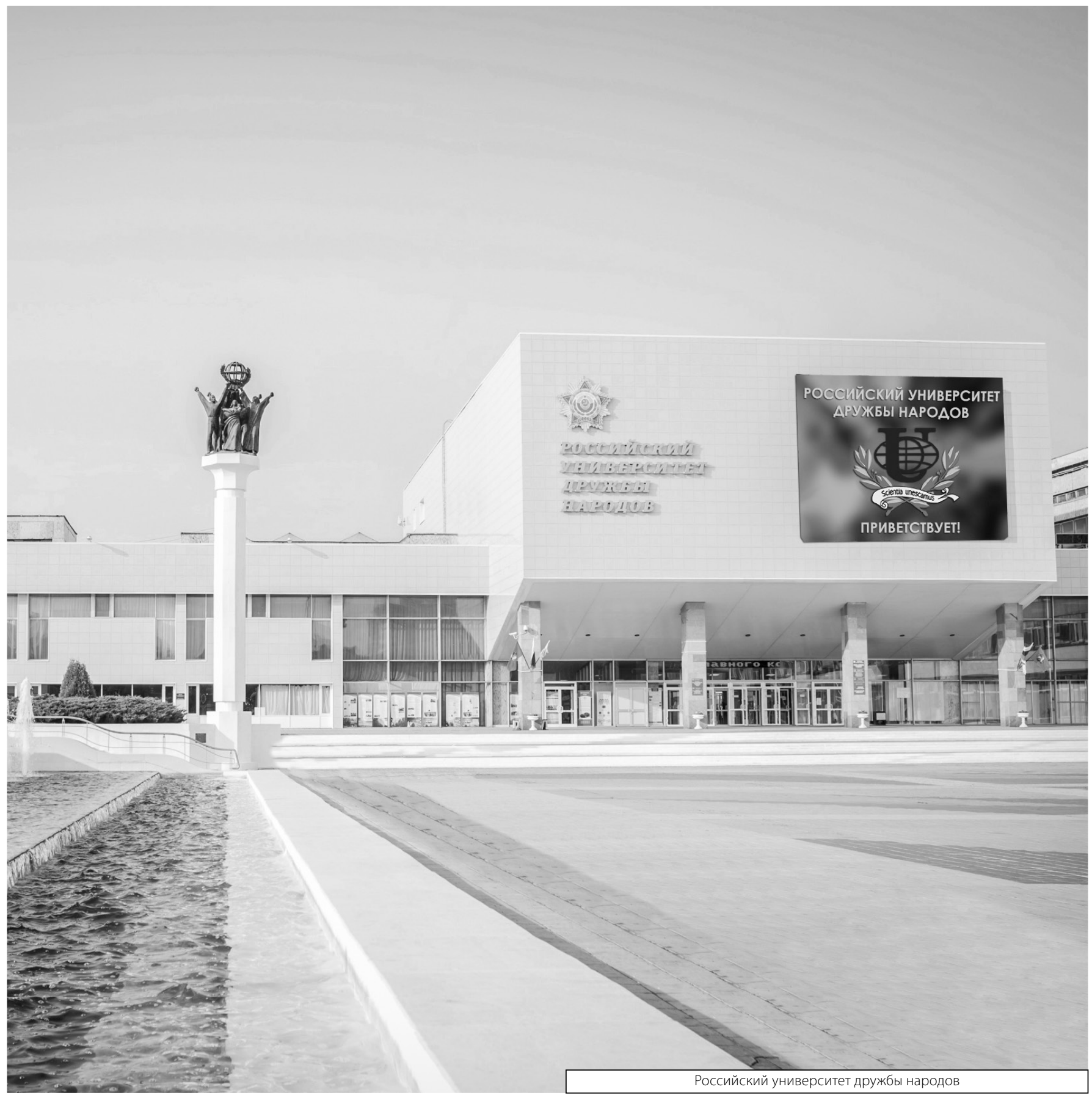

